\title{
Monte Carlo structure simulations for aqueous 1,4-dioxane solutions
}

\author{
Peter I. Nagy ${ }^{a^{*}}$, Gergely Völgyi, ${ }^{b}$ Krisztina Takács-Novák ${ }^{b}$ \\ ${ }^{a}$ Department of Medicinal and Biological Chemistry and the Center for Drug Design and \\ Development, The University of Toledo, Toledo,OH, 43606-3390 \\ e-mail:pnagy@utnet.utoledo.edu \\ ${ }^{b}$ Department of Pharmaceutical Chemistry, Semmelweis University, Högyes E. u. 9, \\ H-1092 Budapest, Hungary
}

Supplementary Information 


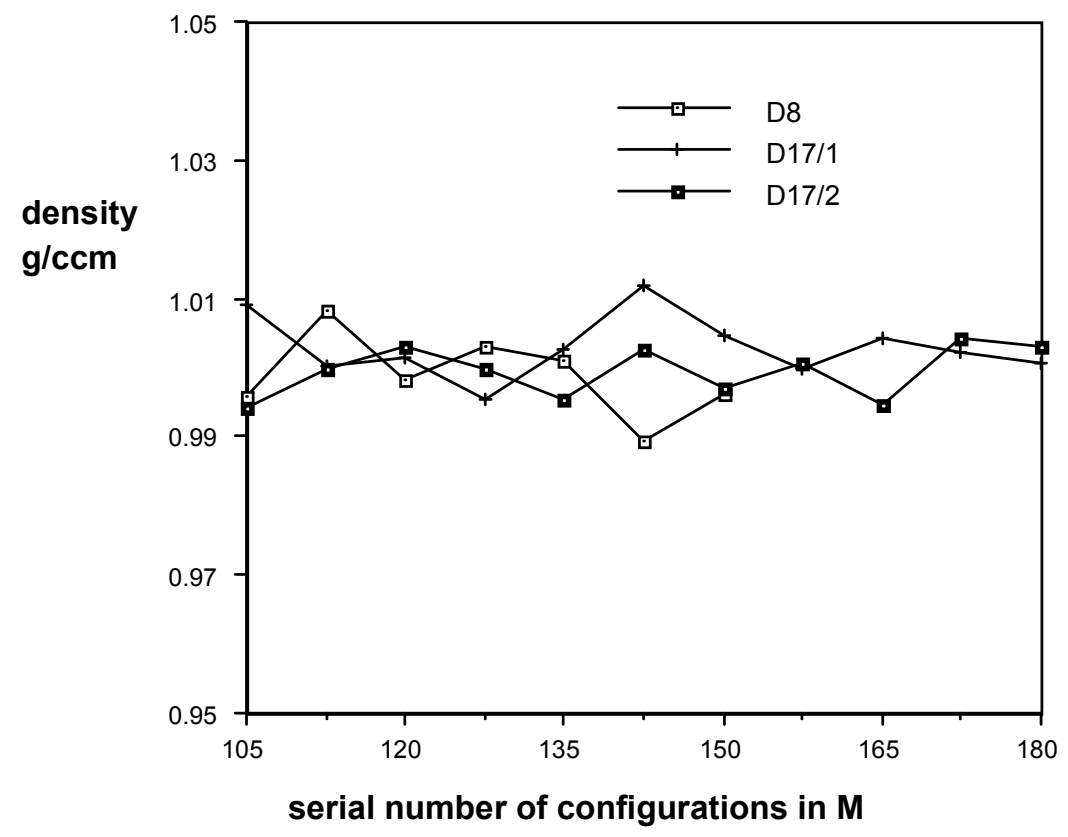

Fig. S1. Changes of the solution densities in $\mathrm{g} / \mathrm{cm}^{3}$. D8 calculated only up to $150 \mathrm{M}$. 


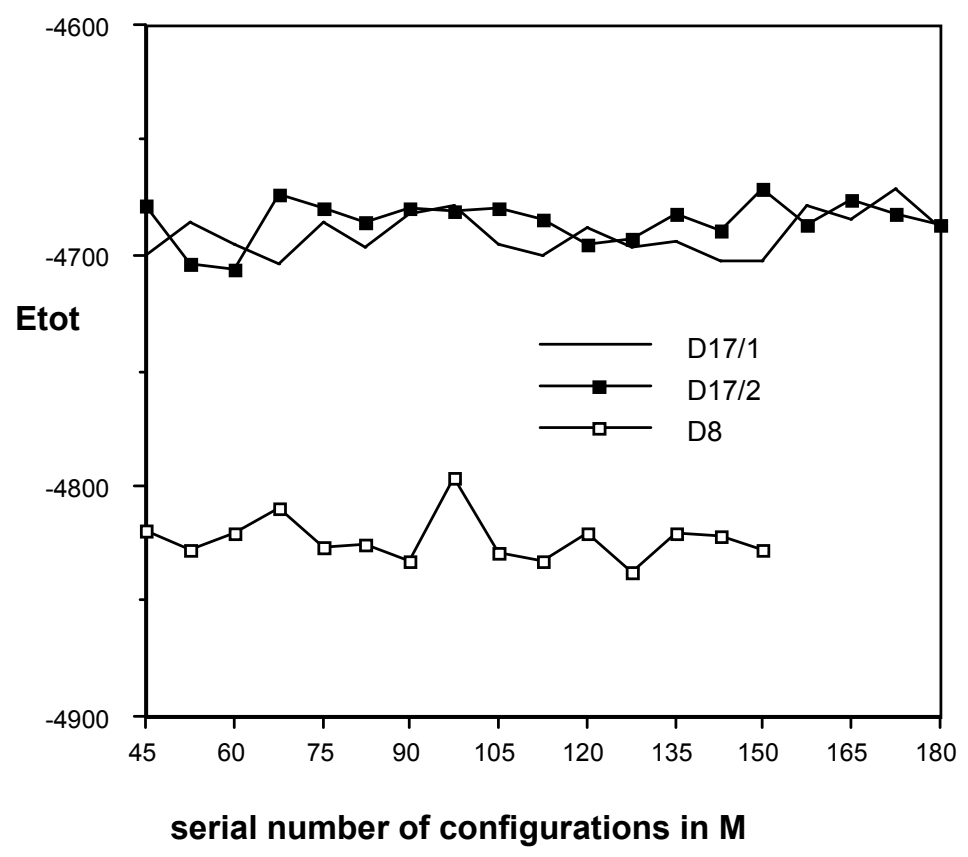

Fig. S12. Changes of the total energies for the model systems in kcal. D8 calculated only up to $150 \mathrm{M}$. 